\title{
Impacto Del Factor Iluminación Y Psicosocial En El Desempeño Laboral Del Personal De Apoyo Y Asistencia A La Educación. Caso: UPIICSA
}

\author{
María Guadalupe Obregón Sánchez \\ Misaela Francisco Márquez \\ Instituto Politécnico Nacional-UPIICSA, Té 950, Col. Granjas México, \\ C.P.08400. Delegación Iztacalco. México, México
}

Doi: 10.19044/esj.2018.v14n4p223 URL:http://dx.doi.org/10.19044/esj.2018.v14n4p223

\begin{abstract}
The adaptation of the work environment in organizations and companies, constitute the essential measures for the prevention of health risks of workers, and is carried out through adjustments and ergonomic studies. It seeks to identify the problems of workers related to their environment, work area, and occupational diseases. Visual problems, headaches, and fatigue are not unrelated to this study and can be derived from poor lighting in the work areas. This research provides the necessary information for the management of physical risks associated with lighting. This, however, ranges from detection and evaluation to some control strategies. The study was carried out within a college campus of the National Polytechnic Institute, in Mexico, which is not excluded from the impact of ergonomic factors. The most wellknown reaction to an inadequate psychosocial situation is stress. Currently, there are various approaches and theoretical models that have studied it. However, all of them have a common element: the relationship between work and the person. Health problems arise when the demands of work are not adapted to the needs, expectations or abilities of the worker or when he or she does not receive adequate compensation, or adequate attention on behalf of their superiors. Another psychosocial risk recognized in the practice of the management of psychosocial risks (without prejudice to its possible typecasting in other preventive disciplines such as ergonomics or safety) is the fatigue of the worker linked to the organization of working time, either due to excess of work time or a lack of rest. It is most commonly manifested in the forms of night work or shifts and in situations of repeated extensions of the workday or lack of proper rest between days. Whatever the case may be, these psychosocial risks usually manifest themselves in an interrelated manner. Stress is a factor that causes violence and vice versa, while fatigue is often accompanied by stressful situations, especially when it results from an
\end{abstract}


excessive workload, monotonous or repetitive work, and lack of rest. Information was obtained regarding the psychosocial factors that are affecting some workers and which have a significant impact on their productivity, their well-being, and their emotional stability. It takes into account stress, economic factors, and internal factors among their co-workers. Ergonomics and productivity are defined so as to carry out the relationship between them, and in order to know the impacts it may have on the worker and on their workspace in the form of discomfort and inconveniences. Methodologically, a questionnaire was administered to a representative sample of workers and the information obtained was subsequently captured in the Statistical Package for Social Science (SPSS) program. The results and graphs were obtained to carry out the interpretation of the results and develop intervention strategies when required. The sum of the physical factor, illumination, and the psychosocial factor show that some of the workers are not comfortable in their job post, resulting to their low productivity.

Keywords: Impact, factors, ergonomics, lighting

\section{Resumen}

La adecuación del entorno de trabajo en las organizaciones y empresas, constituyen las medidas esenciales para la prevención de riesgos para la salud de los trabajadores, y se lleva a cabo por medio de ajustes y estudios ergonómicos. Busca identificar los problemas de los trabajadores relacionados con su entorno, área de trabajo y enfermedades ocupacionales. Los problemas visuales, los dolores de cabeza, la fatiga, no son ajenos a este estudio y se pueden derivar de una mala iluminación en las áreas de trabajo.

Esta investigación proporciona información necesaria para la gestión de riesgos físicos asociados a la iluminación desde la detección y evaluación hasta algunas estrategias de control; está centrada en una escuela de nivel superior del Instituto Politécnico Nacional, en México, que no es ajena al impacto de los factores ergonómicos.

La reacción más conocida ante una situación psicosocial inadecuada es el estrés. Actualmente existen diversos enfoques y modelos teóricos que lo estudian, sin embargo todos ellos tienen un elemento común: la relación entre el trabajo y la persona. Los problemas de salud aparecen cuando las exigencias del trabajo no se adaptan a las necesidades, expectativas o capacidades del trabajador o cuando éste no recibe una adecuada compensación, o una adecuada atención por parte de sus superiores.

Otro riesgo psicosocial reconocido en la práctica de la gestión de los riesgos psicosociales (sin perjuicio de su posible encasillamiento en otras disciplinas preventivas como la ergonomía o la seguridad) es la fatiga del trabajador ligada a la ordenación del tiempo de trabajo, ya sea bien por exceso de tiempo 
de trabajo o por la falta de descanso. Suele manifestarse más comúnmente en las formas de trabajo nocturno o a turnos y en las situaciones de reiterada prolongación de la jornada laboral o falta del debido descanso entre jornadas. En cualquier caso, estos riesgos psicosociales suelen manifestarse de manera interrelacionada. El estrés es un factor causante de violencia y viceversa, mientras que la fatiga suele ir acompañada de situaciones de estrés, especialmente cuando ésta se deriva de una excesiva carga de trabajo, trabajo monótono o repetitivo y falta de descanso.

Se obtuvo información respecto a los factores psicosociales que están afectando a algunos trabajadores y que impacta en su productividad, su bienestar y su estabilidad emocional, tomando en consideración el estrés, los factores económicos y los factores internos con sus compañeros de trabajo.

Se define a la ergonomía y la productividad para llevar a cabo la relación entre ellas y conocer de qué manera impacta con las molestias e incomodidades que el trabajador puede tener en su espacio de trabajo.

Metodológicamente se aplicó un cuestionario a una muestra representativa de trabajadores y posteriormente se capturó la información en el programa Statistical Package for the Social Science, (SPSS), por medio del cual se obtuvieron los resultados y las gráficas, para llevar a cabo la interpretación de resultados y desarrollar las estrategias de intervención cuando se requiera.

La suma del factor físico iluminación y el factor psicosocial detonan que algunos de los trabajadores no estén a gusto en su puesto de trabajo, y por lo tanto su productividad es baja.

Palabras clave: Impacto, factores, ergonomía e iluminación

\section{Introducción}

El estudio ergonómico no es tarea fácil debido al desconocimiento de su contenido. Algunos empresarios cuentan con la capacidad para llevar a cabo algunos estudios que mejoren el ambiente y lugar de trabajo de sus empleados así como lo referente a aspectos psicosociales, para que estén a gusto desempeñando su tarea y como resultado haya productividad y calidad en lo que hacen.

La ergonomía promueve un enfoque holístico centrado en el ser humano para el diseño de los sistemas de trabajo, considerando los factores físicos, cognitivos, sociales, organizacionales y ambientales. Los ergónomos contribuyen al diseño y evaluación de tareas, trabajos, productos, ambientes y sistemas, con el fin de hacerlos compatibles con las necesidades, habilidades y limitaciones de las personas (IEA, 2000-2003). 


\section{Aspectos psicosociales}

\section{El estrés Laboral}

La reacción más conocida ante una situación psicosocial inadecuada es el estrés. Actualmente existen diversos enfoques y modelos teóricos que lo estudian, sin embargo todos ellos tienen un elemento común: la relación entre el trabajo y la persona. Los problemas de salud aparecen cuando las exigencias del trabajo no se adaptan a las necesidades, expectativas o capacidades del trabajador o cuando éste no recibe una adecuada compensación.

El principal referente en esta materia es el «Acuerdo Marco Europeo sobre el Estrés ligado al Trabajo» de 2004, traspuesto al marco español de negociación colectiva en el anexo del ANC 2005 (BOE de 16.3.05). En este Acuerdo el estrés laboral se describe como «un estado que se acompaña de quejas o disfunciones físicas, psicológicas o sociales y que es resultado de la incapacidad de los individuos de estar a la altura de las exigencias o las expectativas puestas en ellos».

El estrés es un fenómeno complejo del que se derivan enfermedades y trastornos de carácter físico, psíquico o conductual cuyo origen no solamente puede hallarse en la concurrencia de factores de riesgo psicosocial en la organización y entorno social de la empresa sino también en la presencia de otros agentes como el ruido, las vibraciones, temperaturas elevadas, mala ventilación, mala iluminación, entre otros.

\section{La Violencia en el Trabajo}

En segundo lugar, se encuentra la violencia en el trabajo, que se trata de un concepto emparentado con el anterior ya que el Acuerdo Europeo sobre el

Estrés Laboral reconoce que «el acoso y la violencia en el lugar de trabajo son factores potenciales de estrés». La diferencia es que la violencia conlleva siempre una conducta de maltrato o agresión ilegítima hacia otras personas.

La violencia puede ser tanto física como psicológica y dentro de esta última se encuentran todas las formas de acoso laboral.

Abarca tanto la denominada violencia interna, que es la que se manifiesta entre el personal que presta servicios en el mismo centro o lugar de trabajo, como la violencia externa o de terceros, que es aquella que puede darse con respecto a personas que no prestan servicios en el centro de trabajo y son meros clientes o usuarios del mismo o incluso personas cuya presencia o actividad no es legítima.

La violencia interna tiene como referente el Acuerdo Marco Europeo sobre Violencia y Acoso de 2007 (traspuesta al marco español de negociación colectiva en el anexo del ANC de 2007, publicado en el BOE de 14.1.2008), mientras que la violencia y acoso externo o de terceros tiene como referente 
las Directrices Multisectoriales Europeas aprobadas por los interlocutores sociales europeos en 2010.

\section{La fatiga derivada de la ordenación del tiempo de trabajo}

El tercer riesgo psicosocial reconocido en la práctica de la gestión de los riesgos psicosociales (sin perjuicio de su posible encasillamiento en otras disciplinas preventivas como la ergonomía o la seguridad) es la fatiga del trabajador ligada a la ordenación del tiempo de trabajo, ya sea bien por exceso de tiempo de trabajo o por la falta de descanso. Suele manifestarse más comúnmente en las formas de trabajo nocturno o a turnos y en las situaciones de reiterada prolongación de la jornada laboral o falta del debido descanso inter jornadas.

En cualquier caso, estos tres riesgos psicosociales suelen manifestarse de manera interrelacionada. El estrés es un factor causante de violencia y viceversa, mientras que la fatiga suele ir acompañada de situaciones de estrés, especialmente cuando ésta se deriva de una excesiva carga de trabajo, trabajo monótono o repetitivo y falta de descanso.

\section{Iluminación}

Según el ministerio de trabajo y seguridad social, (Alvarez Bayona, 2015); "La iluminación es una parte fundamental en el acondicionamiento ergonómico de los puestos de trabajo. Si bien, el ser humano tiene una gran capacidad para adaptarse a las diferentes calidades lumínicas, una deficiencia en la misma puede producir un aumento de la fatiga visual, una reducción en el rendimiento, un incremento en los errores y en ocasiones incluso accidentes.

Un adecuado análisis de las características que deben disponer los sistemas de iluminación, la adaptación a las tareas a realizar y las características individuales, son aspectos fundamentales que se deben considerar.

En la misma publicación destacan los aspectos que se deben conocer sobre la luz y las propiedades lumínicas para diseñar un ambiente lumínico correcto:

- $\quad$ Flujo luminoso (Lm)

- Intensidad luminosa (I Cd)

- $\quad$ Nivel de iluminación (Lx)

- Luminancia $\left(\mathrm{Cd} / \mathrm{m}^{2}\right)$

- Contraste

La luz al comportarse como una onda electromagnética, se manifiesta en nuestro rango visible, entre los 380 y 760 nanómetros, nuestro ojo percibe las diferencias de luz y así se diferencian los colores, las propiedades ópticas están relacionadas con esta radiación, la luz puede sufrir reflexiones, refracciones, transmisiones y absorciones. 
Es primordial y necesario definir los siguientes conceptos: luz, iluminar, y corriente eléctrica. Por lo tanto, con el fin de abordarlos desde un punto de vista práctico se propone consultar el diccionario de la Real Academia de la lengua Española. Las definiciones de los conceptos se presentan a continuación:

Luz: f. Agente físico que hace visibles los objetos.

f. Claridad que irradian los cuerpos en combustión, ignición o incandescencia.

Iluminar: Alumbrar, dar luz o bañar de resplandor. conductor.

Corriente eléctrica: f. Flujo de cargas eléctricas a través de un

f. corriente Eléctrica. Magnitud física que expresa la cantidad de electricidad que fluye por un conductor en la unidad de tiempo, y cuya unidad en el sistema internacional es el amperio.

Por otro lado, la iluminación es la densidad de luz incidente sobre una superficie por unidad de área, expresada en luxes1 (Harvey et al., 2015; STPS, 2008). Y finalmente la corriente eléctrica es un tipo de energía que mediante el empleo de algún tipo de tecnología es posible iluminar algún espacio.

Con base en lo anterior y encausando el tema hacia la ergonomía la iluminación es un factor esencial para los puestos de trabajo en toda empresa, pues busca evitar causar daños en la visión del trabajador, así como disminuir errores y accidentes; ya que la visión es el canal sensorial primario de información que utilizamos al desplazarnos y en el que se deposita toda la confianza (Harvey et al., 2015).

En la antigüedad, en las construcciones se buscaba maximizar la luz natural que proporciona el Sol durante el día; posteriormente, con la intervención del invento de la bombilla eléctrica en 1879 y la formalización de la luz eléctrica como un servicio público en 1880, la iluminación por medio de energía eléctrica se comenzó a emplear en las actividades cotidianas, domesticas e industriales; sin embargo, hasta 1950 se implantó de forma definitiva en las empresas (Obregón, 2016).

Por lo tanto, con base en la definición de iluminación y teniendo en cuenta su gran versatilidad (con el empleo de algún tipo de tecnología) en diferentes actividades laborales de la época industrializada, surge la intención por determinar la relación existente entre una actividad y la luminosidad necesaria para llevarla a cabo, abarcando las particularidades del usuario y las características del lugar de trabajo, en donde para este último se adopta alguna de los siguientes tipos: del piso.

1. Iluminación general: luz distribuida a tres metros o más por encima

2. Iluminación general localizada: busca direccionar la luz hacia el espacio de trabajo. 
3. Iluminación suplementaria: se requieren fuentes adicionales de iluminación, debido a la exigencia de precisión y detalles de alguna operación.

4. Iluminación de emergencia: se enfoca principalmente en la señalización y conducción hacia las salidas de emergencia, sin intervenir en operaciones de producción.

5. Iluminación espacial: se caracteriza por tener una exigencia visual elevada mayor de 1000 luxes o menor de 100 luxes, esto para la rapidez de funcionamiento del ojo y exactitud con que se lleva a cabo la actividad.

Sin duda que teniendo alguno de los tipos anteriores de iluminación, se garantiza un ambiente de trabajo limpio, protegido y ordenado. Sin embargo, tomando en cuenta la inesperada situación de un siniestro; para la señalización hacia las salidas de emergencia Harvey (2016) sugiere que se debe obedecer la iluminación mínima propuesta por Simmons (1975) de 0.28 luxes (o 0.24 propuesta por Jaschinski en 1982) a lo largo del pasillo (o iconos visuales) que conduce hacia una salida de emergencia; mientras que Oullette y Rea (1989) concluyen que la iluminación que es suficiente para no chocar con obstáculos de gran tamaño y moverse lo más rápido posible es de 0.5 luxes.

Regresando al ambiente laboral, además de cubrir con alguno de los tipos de iluminación, es necesario llevar a cabo una revisión periódica que cubra los siguientes puntos:

a) Cantidad de luz: midiéndose con un luxómetro.

b) Uniformidad: proyección homogénea sobre el plano de trabajo.

c) Sombra e iluminación localizada: evitar la generación de sombras.

d) Cubrimiento de focos y deslumbramiento: factores que afectan la comodidad visual, tales como: forma y dimensión del área de trabajo, nivel de iluminación, tipo de luminarias, luminancia de todo el campo de visión, situación del observador, línea de visión, implementos y accesorios.

e) Tipo adecuado de reflectores: selección con base en el análisis de la actividad laboral.

f) Mantenimiento, principalmente relacionado con la limpieza del área de emisión, ya que la suciedad resta iluminación.

g) Operación de lámparas con voltaje específico,

h) Condiciones de ruptura y exposición: lo primero puede provocar un accidente cuando se manejan voltajes altos, mientras que el segundo se debe evitar la incomodidad y quemaduras por contacto accidental con la fuente de emisión.

En este punto es necesario señalar que los investigadores en este ámbito no son autoridad en seguridad, es decir, la ciencia puede ayudar a explicar de manera sencilla las ventajas de adoptar diferentes normas en términos de: rendimiento humano bienestar y seguridad. Sin embargo, el 
trabajador al igual que la empresa, tienen una gran responsabilidad y compromiso con su lugar de trabajo.

\section{La iluminación en el ambiente de trabajo} esto evitarlos.

1. Reducción de accidentes, ya que es posible reconocer riesgos y con

2. Reducción de errores o defectos, su reconocimiento es más rápido y sin forzar la vista.

3. Mayor orden y limpieza, pone en evidencia la acumulación de residuos y desperdicios que se deben eliminar para tener una mejor armonía en el área de trabajo.

4. Incremento de la moral o bienestar, un menor esfuerzo en la vista disminuye la tensión nerviosa, provocando un ambiente más cálido y satisfactorio en el trabajador, sin producir fatiga.

En algunos ámbitos laborales, los puntos anteriores son muy fáciles de lograr siguiendo las sugerencias de las normas establecidas; sin embargo ¿qué pasa cuando el lugar de trabajo es la cabina de una aeronave en pleno vuelo? Ámbito para el que 58 accidentes de aviación entre 1980 y 1998 fueron problemas relacionados con la visión del piloto, resultado de una exposición a la luz de fuentes emisoras brillantes (tablero de control) durante vuelo nocturno (Nakawara et al., 2007).

Tomando en cuenta lo anterior, Curtis (1962) presenta que a 10,000 pies de altura, un piloto está expuesto a 11,800 pies-candelas (127,015 luxes), mientras que a nivel del mar, la exposición es aproximadamente de 10,000 pies-candelas (107,640 luxes); además de mencionar que su visión está expuesta a diversas condiciones meteorológicas que pueden afectar su habilidad durante alguna toma de decisión, particularmente durante la noche.

Para el caso del ambiente laboral terrestre, las condiciones de iluminación deficiente o en exceso son las principales causas de la fatiga visual, esfuerzo mental, accidentes, falta de adaptación y de bienestar.

Afortunadamente se han formulado normas que sugieren los niveles mínimos de intensidad de iluminación (en luxes) para cada actividad laboral (Grupo A: superior a 100 pies-bujías, Grupo B: de 50 a 100 pies-bujías, y Grupo C: de 30 a 50 pies-bujías), así como la sugerencia de una revisión médica anual del estado físico y de salud visual del trabajador.

Con el propósito de complementar y profundizar en los temas que comprenden a la iluminación, es necesario llevar a cabo una investigación de la anatomía y fisiología del ojo humano; estudio que hace posible comprender su interacción y factores de gran importancia como:

a) Adaptación al nivel de iluminación,

b) Agudeza visual,

c) Velocidad de percepción, 
d) Sensibilidad a los contrastes, y

e) Visión de profundidad.

Obregón (2016) sugiere algunos aspectos importantes del comportamiento fisiológico y anatómico del ojo humano, con los cuales no se desvía el propósito del alumbrado: "hacer posible la visión".

- Incrementar el uso de la luz natural,

- Iluminar el área de trabajo y minimizar los cambios de luminosidad,

- Eliminar las superficies brillantes del campo de visión del trabajador, y

- Usar colores claros para las paredes y techos cuando se requieran mayores niveles de iluminación

Por otro lado, la norma oficial mexicana NOM-025-STPS-2008, Condiciones de iluminación en los centros de trabajo; que tiene como objetivo principal establecer las características de iluminación en los centros de trabajo, de tal forma que no sea un factor de riesgo para la salud de los trabajadores al realizar sus actividades; contiene puntos importantes tales como:

- Métodos para evaluar los niveles de iluminación,

- Obligaciones del patrón,

- Obligaciones de los trabajadores, y

- Tratamiento de la información recabada durante un estudio de iluminación laboral.

El gran aporte de la investigación realizada hasta ahora en materia de iluminación es la demostración de que con una adecuada emisión de densidad de flujo luminoso en el área de trabajo y de manera enfocada sobre la actividad a realizar, es notable el incremento en la productividad del trabajador, además de la reducción del número de accidentes.

Los accidentes y la iluminación son un binomio de factores de gran relación con las actividades domésticas, recreativas y de esparcimiento. Sobre todo para el caso de presentarse algún siniestro, la iluminación en la señalización es de gran ayuda para las personas que estén presentes en el suceso (sobre todo si ocurre durante la noche), está comprobado que en cualquier tipo de actividad, un ser humano (con la visión activa) deposita toda su confianza en sus representaciones visuales, de esta manera busca tomar la mejor decisión; para este caso es la búsqueda de un lugar seguro para permanecer durante el episodio de peligro.

Por otro lado, es importante señalar que el ser humano ha aprovechado su conocimiento sobre este factor (iluminación) en beneficio de la supervivencia de su especie, algunos ejemplos son la iluminación en la producción de las granjas avícolas (Castelló, 2013) o en la producción de comida orgánica (Darko et al., 2014), demostrándose la versatilidad del empleo de la iluminación en otros campos en donde el ser humano aparentemente tiene una interacción indirecta. 


\section{Metodología}

La presente investigación es mixta ya que se utiliza el método cuantitativo y el método cualitativo, así como descriptivo dando a conocer la problemática que impacta al personal. Con el método cuantitativo conoceremos el número de personas que se ven afectadas con cada uno de los factores a estudiar. Con el método cualitativo, conoceremos las variables y sus características que nos hacen pensar en la afectación que sufre el personal de apoyo y asistencia a la educación, (PAAE).

La presente investigación se desarrolló de la siguiente manera. Se solicitó información del personal de apoyo y asistencia a la educación, (PAAE), para conocer el total del personal. La información proporcionada fue que en total son 346 trabajadores de los cuales 240 se encuentran laborando en el turno matutino y 93 , en el turno vespertino.

Se aplicó la fórmula estadística para obtener la muestra a la que se aplicaría el instrumento de recolección de datos, quedando de la siguiente manera:

Universo 346 personas

Fórmula

Donde:

$$
n=\frac{N p(1-p) Z_{1-\alpha}^{2}}{(N-1) \varepsilon^{2}+p(1-p) Z_{1-\alpha}^{2}}
$$

$\mathrm{n}=$ Tamaño de la muestra

$\mathrm{N}=$ Población $=346$

$Z_{1-\alpha}=$ Valor en tablas de distribución normal

$\propto=0.95$

$1-\propto=1-0.95=0.05 \rightarrow Z=1.96$

$Z_{1-\propto}=$ Valor en tablas de distribución normal para probabilidad central de $1-\propto=$ (queremos un $95 \%$ de confianza.

$\varepsilon=$ Error muestral permitido (entre 0.05 y $0.08 \%$ )

$\sigma P=$ Variabilidad positiva.

Previa es $=$ a 0.50

$\mathrm{n}=105$ encuestados.

$$
n=\frac{346(0.5)(1-0.5)(1.96)^{2}}{\left[(346-1)(0.08)^{2}+(0.5)(1-0.5)(1.96)^{2}\right]}
$$

APLICACIÓN

Se llevó a cabo el pilotaje del cuestionario, el cual se estructuró con preguntas básicas respecto a iluminación, y algunas respecto a aspectos psicosociales que pueden impactar al trabajador, en su puesto de trabajo.

Se determinó pilotear 30 cuestionarios, 15 en el turno matutino y 15 en el turno vespertino, debido a que la muestra es pequeña. 
De los 346 (PAAE), 240 se comentó anteriormente pertenecen al turno matutino. Con un porcentaje aplicado a ambos turnos tenemos que:

$240 \times 30.35 \%=$ a 73 (PAAE), turno matutino hay que aplicar el cuestionario.

$93 \times 30.35 \%=$ a 29 (PAAE), del turno vespertino hay que aplicar el cuestionario.

$73+29=102$

Nota: Nos hacen falta 3 cuestionarios para que nos den los 105 que se tienen que aplicar, por lo tanto los sumaremos al turno vespertino tomando en consideración y como justificación, que son menos. En total se aplicarán 32 cuestionarios en el turno vespertino.

Se pilotearon 30 cuestionarios, obteniendo un alfa de Crombach de 8.87; por tal razón es confiable aplicar el instrumento de recolección de datos.

El programa para el análisis de los datos es el Statistical Package for the Social Sciences, (SPSS).

Se llevó a cabo la aplicación de los cuestionarios y se procedió a la introducción de los datos, obteniendo los siguientes resultados.

¿Considera que es adecuada la iluminación en su área de trabajo?

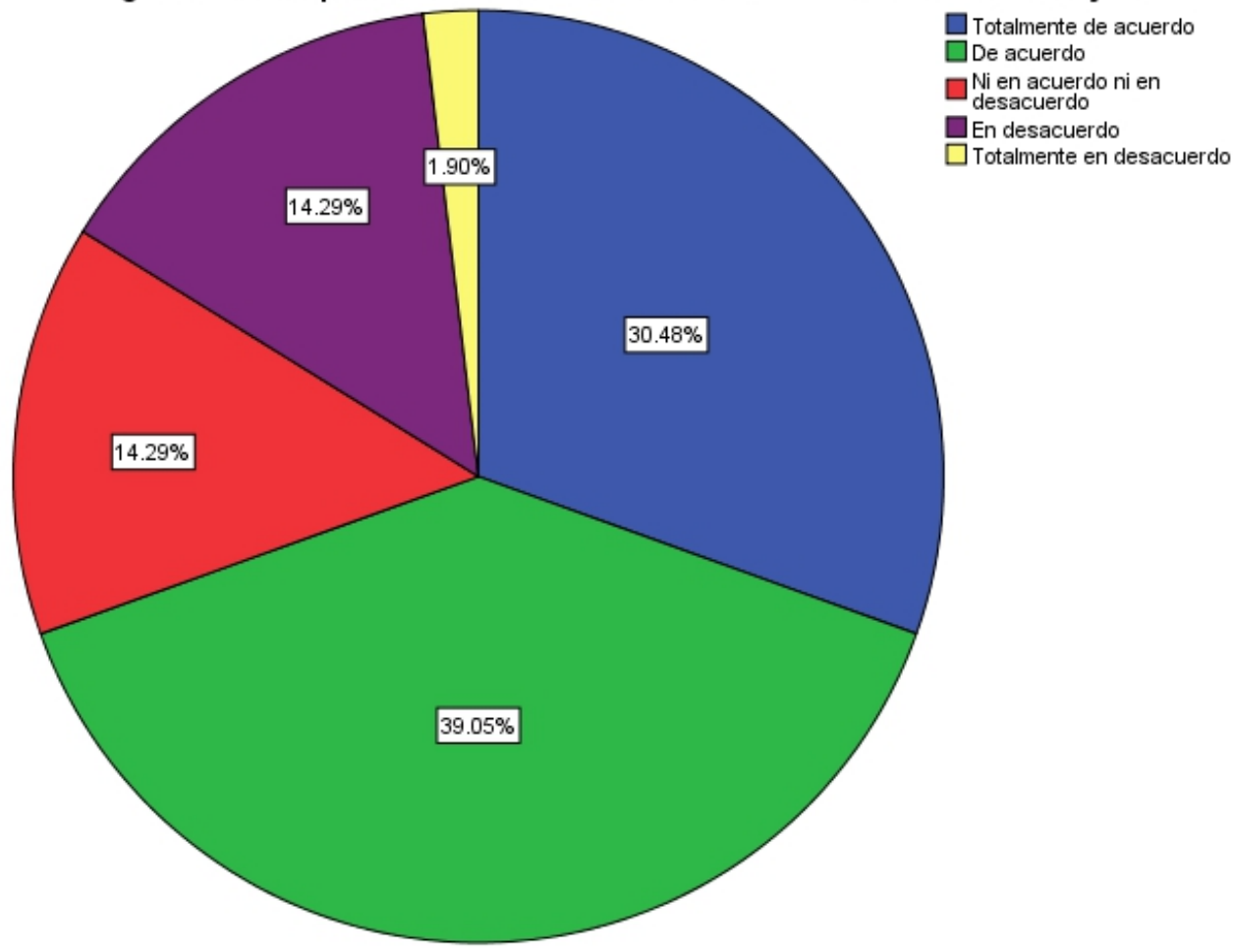

Respecto a esta pregunta los resultados fueron los siguientes: El 39.05 por ciento de los trabajadores considera estar totalmente de acuerdo en que es 
adecuada la iluminación en su área de trabajo. El 30.48 por ciento considera estar de acuerdo en que es adecuada la iluminación, el 1.90 por ciento está totalmente en desacuerdo que la iluminación en su área de trabajo se adecuada, el 14.29 por ciento está en desacuerdo de que la iluminación en su área de trabajo sea adecuada, y el 14.29 por ciento no sabe si la iluminación en su área de trabajo sea adecuada.

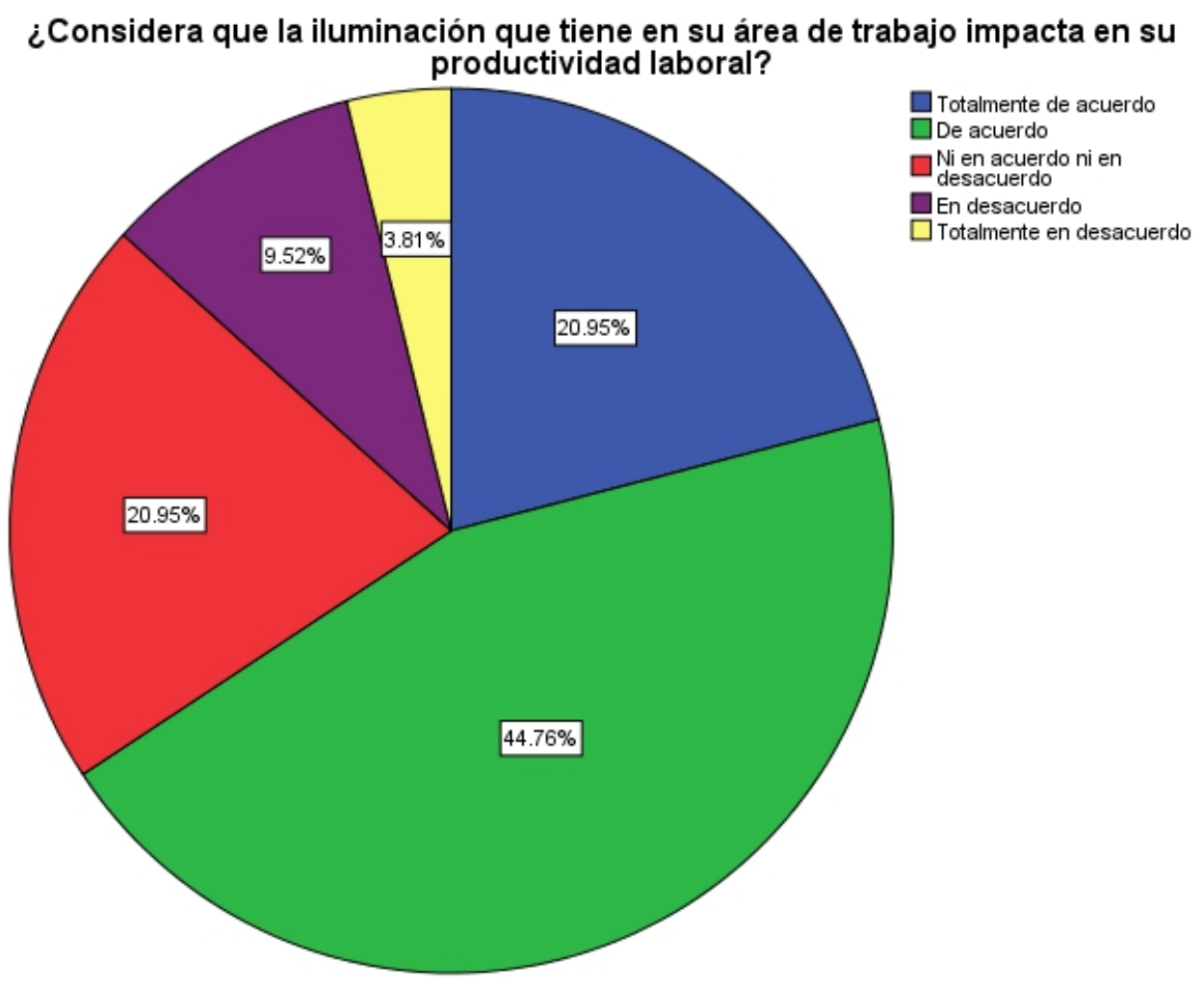

El 20.95\% del personal está totalmente de acuerdo que la iluminación que tiene en su área de trabajo, sí impacta a su productividad laboral, el $44.76 \%$ está de acuerdo en que la iluminación que tiene en su área de trabajo impacta a su productividad laboral, el $20.95 \%$ del personal, no sabe si la iluminación que tiene en su área de trabajo impacta o no, su productividad laboral, el 9.52\% del personal está en desacuerdo de que la iluminación en su área de trabajo, impacta su productividad laboral y el 3.81\% del personal, está totalmente en desacuerdo de que la iluminación en su área de trabajo impacta en su productividad laboral. 


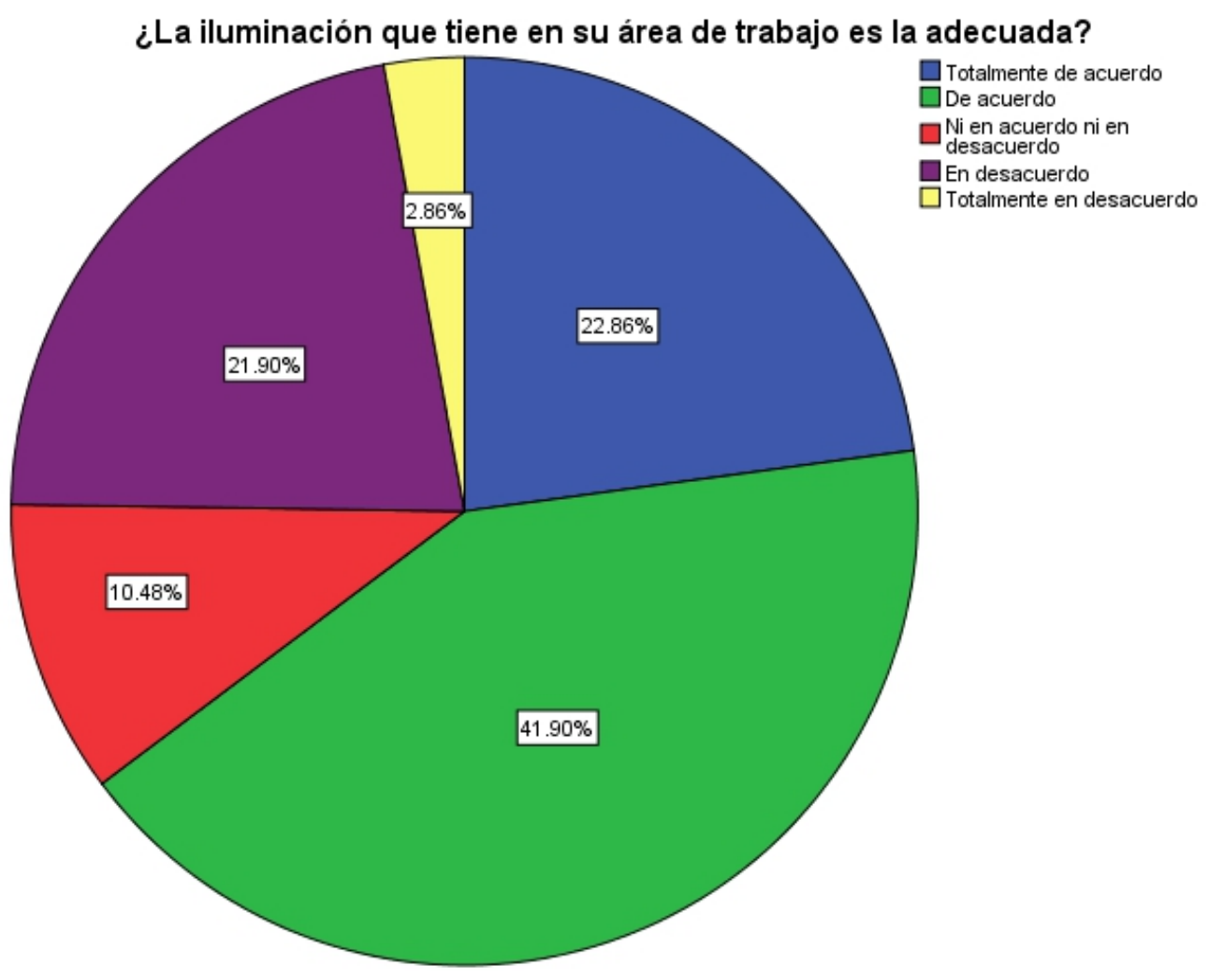

El 41.90\% del personal considera que la iluminación en su área de trabajo es la adecuada, mientras que el 10.48 por ciento del personal no sabe si es adecuada o no. El 22.86 por ciento, está totalmente de acuerdo en que la iluminación que tiene en su área de trabajo es la adecuada. El 21.90 por ciento considera que la iluminación en su puesto de trabajo no es la adecuada y el 2.86 por ciento considera estar totalmente en desacuerdo de que la iluminación en su puesto de trabajo sea la adecuada. Del personal considera que la iluminación en su área de trabajo es la adecuada, mientras que el 10.48 por ciento del personal no sabe si es adecuada o no. El 22.86 por ciento, está totalmente de acuerdo en que la iluminación que tiene en su área de trabajo es la adecuada. El 21.90 por ciento considera que la iluminación en su puesto de trabajo no es la adecuada y el 2.86 por ciento considera estar totalmente en desacuerdo de que la iluminación en su puesto de trabajo sea la adecuada. 


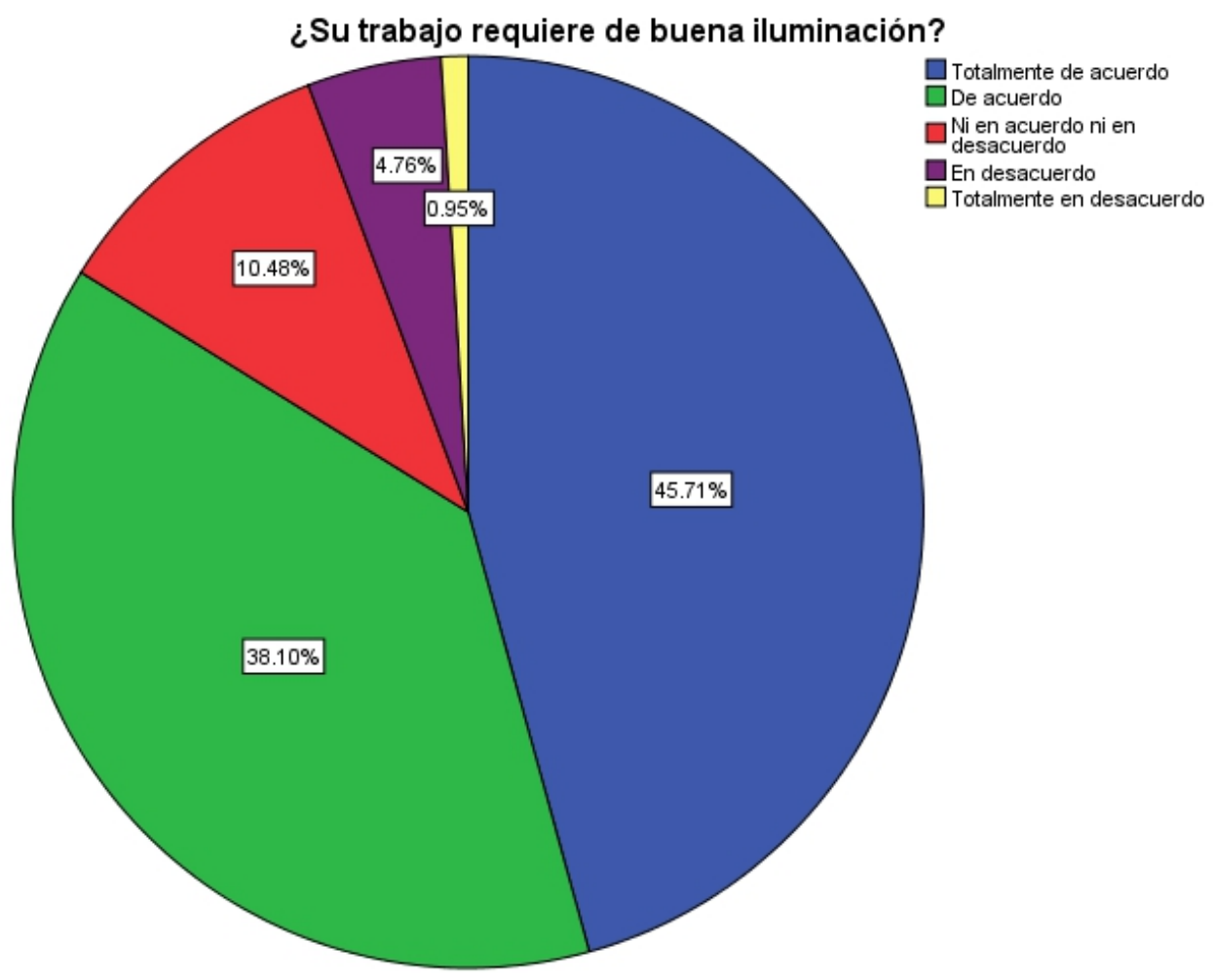

El $45.71 \%$ del personal está totalmente de acuerdo que su trabajo requiere de buena iluminación, mientras que el 38.10 por ciento está de acuerdo que requiere de buena iluminación. El 10.48 por ciento contestó estar ni de acuerdo ni en desacuerdo, el 4.76 por ciento contestó estar totalmente en desacuerdo que requiera de buena iluminación en su trabajo, y el 0.95 por ciento está totalmente en desacuerdo que necesite de una buena iluminación en su área de trabajo. 


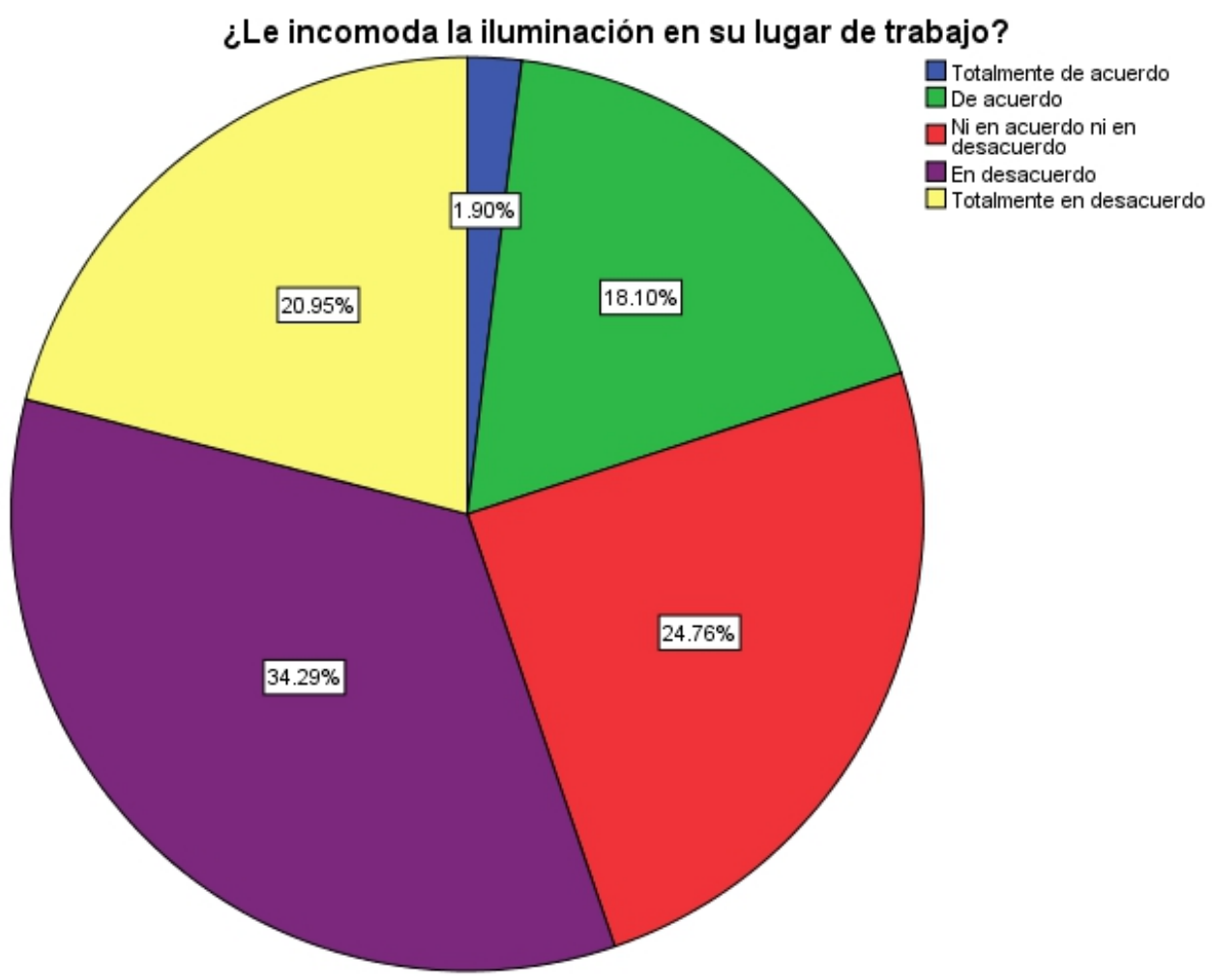

El 1.90\% contestó estar totalmente de acuerdo que le incomoda la iluminación en su lugar de trabajo, el $18.10 \%$ está de acuerdo que le incomoda la iluminación en su lugar de trabajo, el $24.76 \%$ contestó que ni en acuerdo ni en desacuerdo, es decir no sabe, sí o no le incomoda la iluminación en su lugar de trabajo, el 34.29\% está en desacuerdo que le incomoda la iluminación en su lugar de trabajo, el $20.95 \%$ está en desacuerdo que le incomoda la iluminación en su lugar de trabajo, y el 1.90\% está totalmente en desacuerdo que le incomoda la iluminación en su lugar de trabajo. 


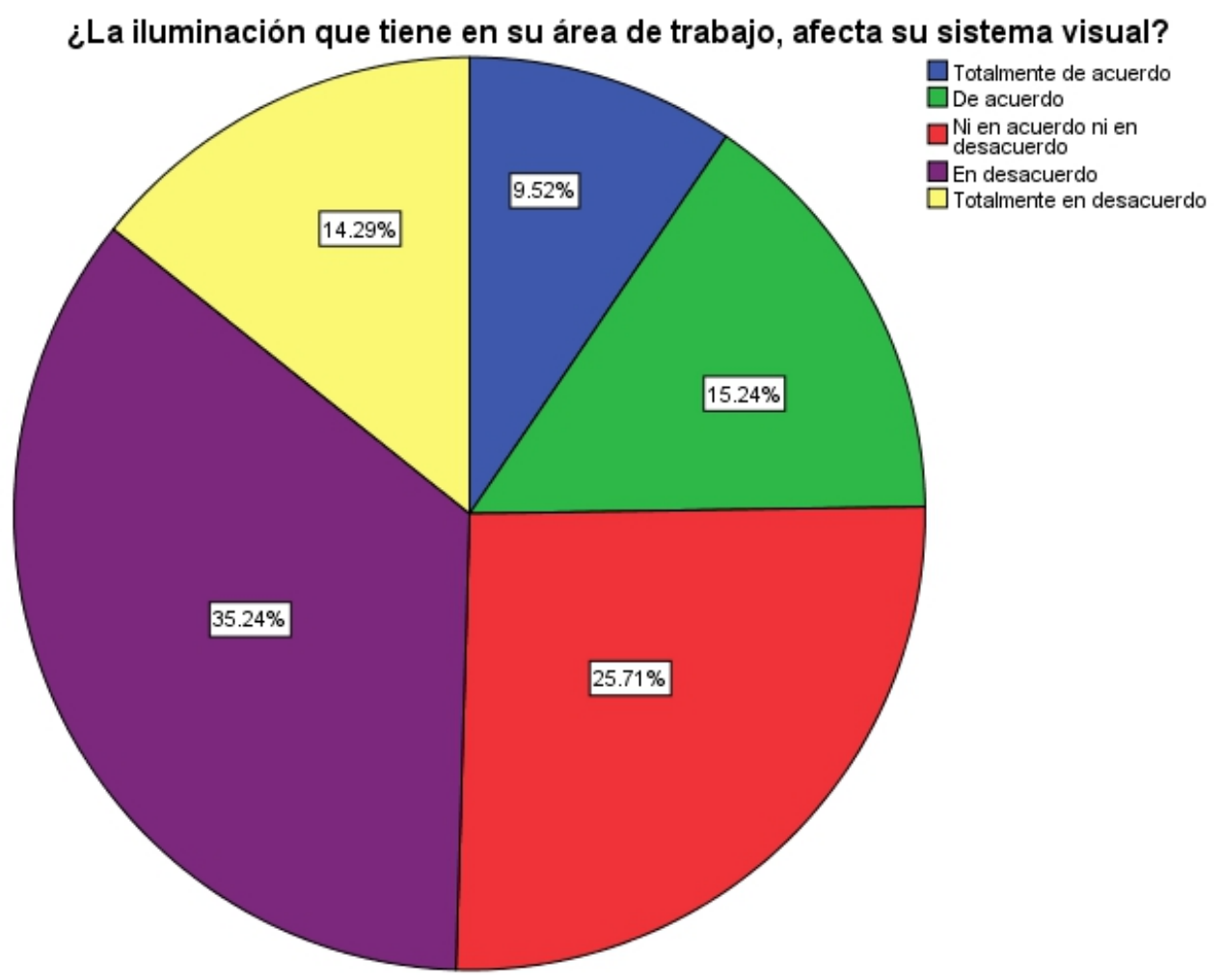

El 9.52\% de los trabajadores contestaron que están totalmente de acuerdo en que la iluminación que tienen en su área de trabajo, afecta su sistema visual, mientras que el $15.24 \%$ contestó estar de acuerdo que la iluminación que tienen en su área de trabajo, afecta su sistema visual. El $25.71 \%$ del personal contesto que ni en acuerdo ni en desacuerdo, es decir no saben si la iluminación les afecta su sistema visual, el 35.24\% contestó estar en desacuerdo, es decir consideran que no les afecta la iluminación que tiene el área de trabajo, en su sistema visual, y $14.29 \%$ está totalmente en desacuerdo que le afecte su sistema visual, la iluminación que tiene en su área de trabajo 


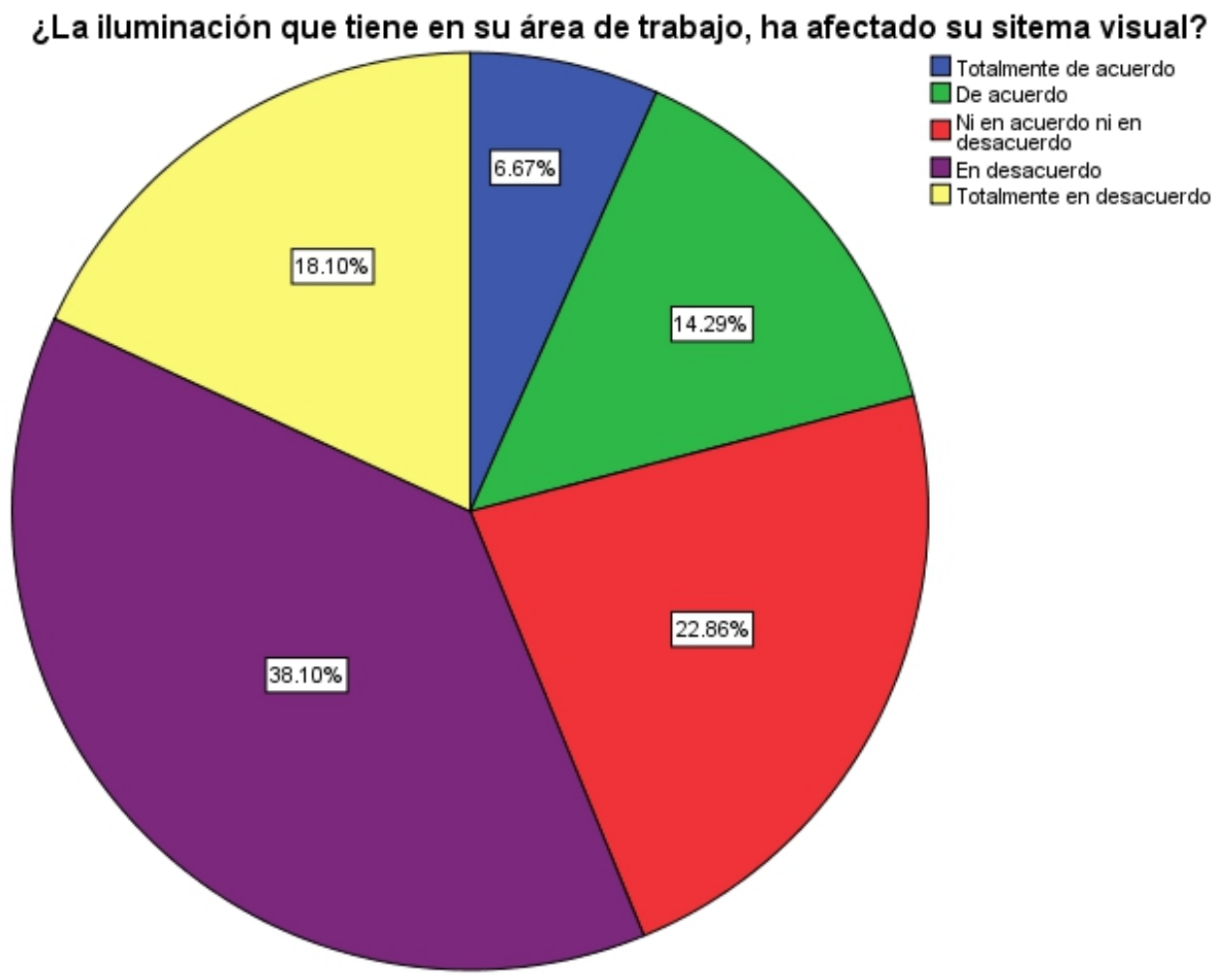

El $6.67 \%$ del personal de apoyo contestó estar totalmente de acuerdo en que la iluminación que tiene en su área de trabajo, ha afectado su sistema visual, mientras que el $14.29 \%$ contestó estar de acuerdo en que la iluminación que tiene en su área de trabajo, ha afectado su sistema visual. El $22.86 \%$ contestó ni en acuerdo ni en desacuerdo, es decir no saben sí o no, la iluminación que tienen en su área de trabajo, ha afectado su sistema visual. 


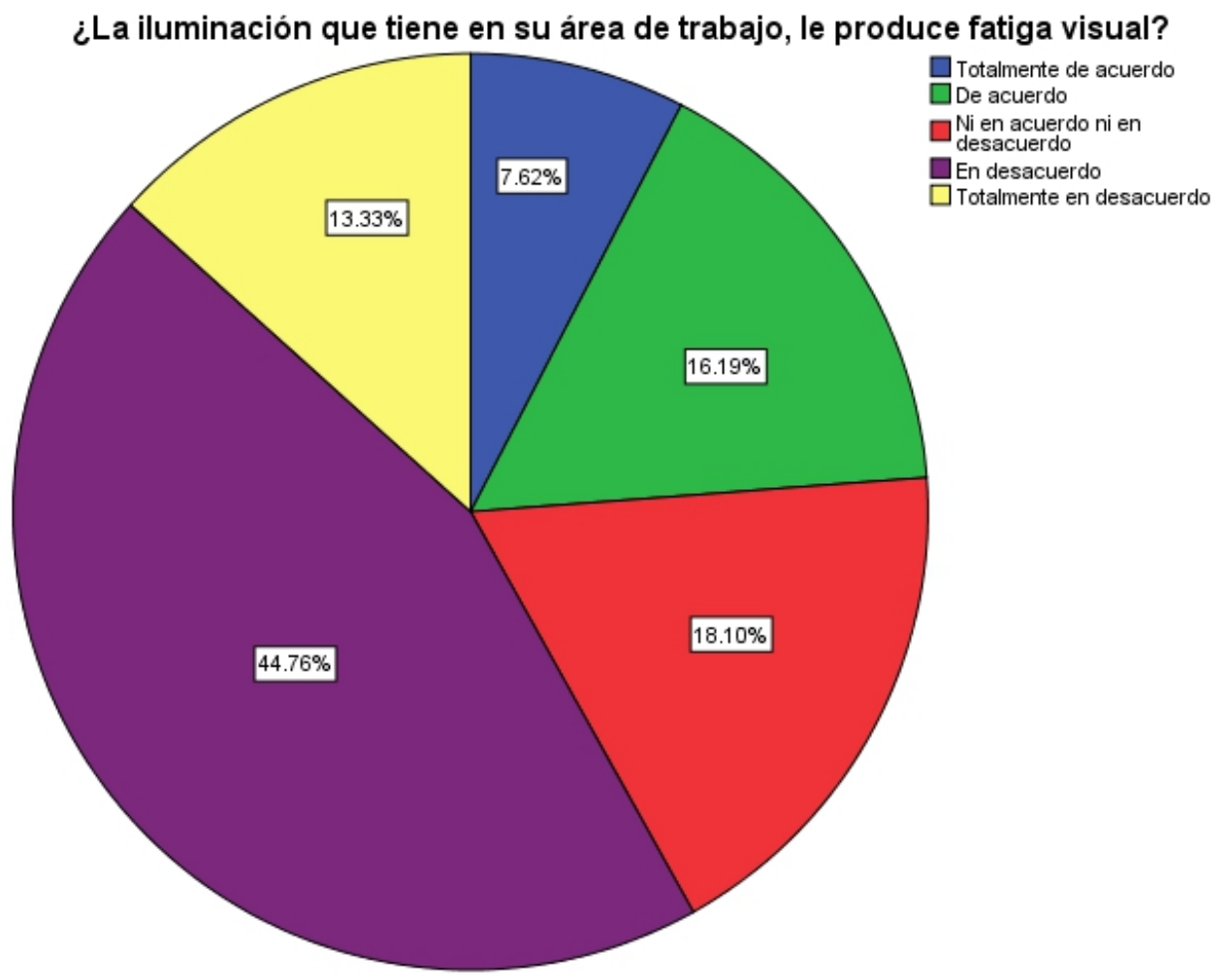

El 7.62\% del personal contestó que está totalmente de acuerdo en que la iluminación que tiene en su área de trabajo, le produce fatiga visual, mientras que el $16.19 \%$ contestó que está de acuerdo en que la iluminación que tiene en su área de trabajo, le produce fatiga visual. El 18.10\% contestó que ni de acuerdo ni en desacuerdo, es decir no sabe si la iluminación que tiene en su área de trabajo, le produce fatiga visual, el 44.76\% del personal está en desacuerdo que la iluminación que tiene en su área de trabajo, le produzca fatiga visual, y $13.33 \%$ está totalmente en desacuerdo que la iluminación que tiene en su área de trabajo, le produce fatiga visual. 


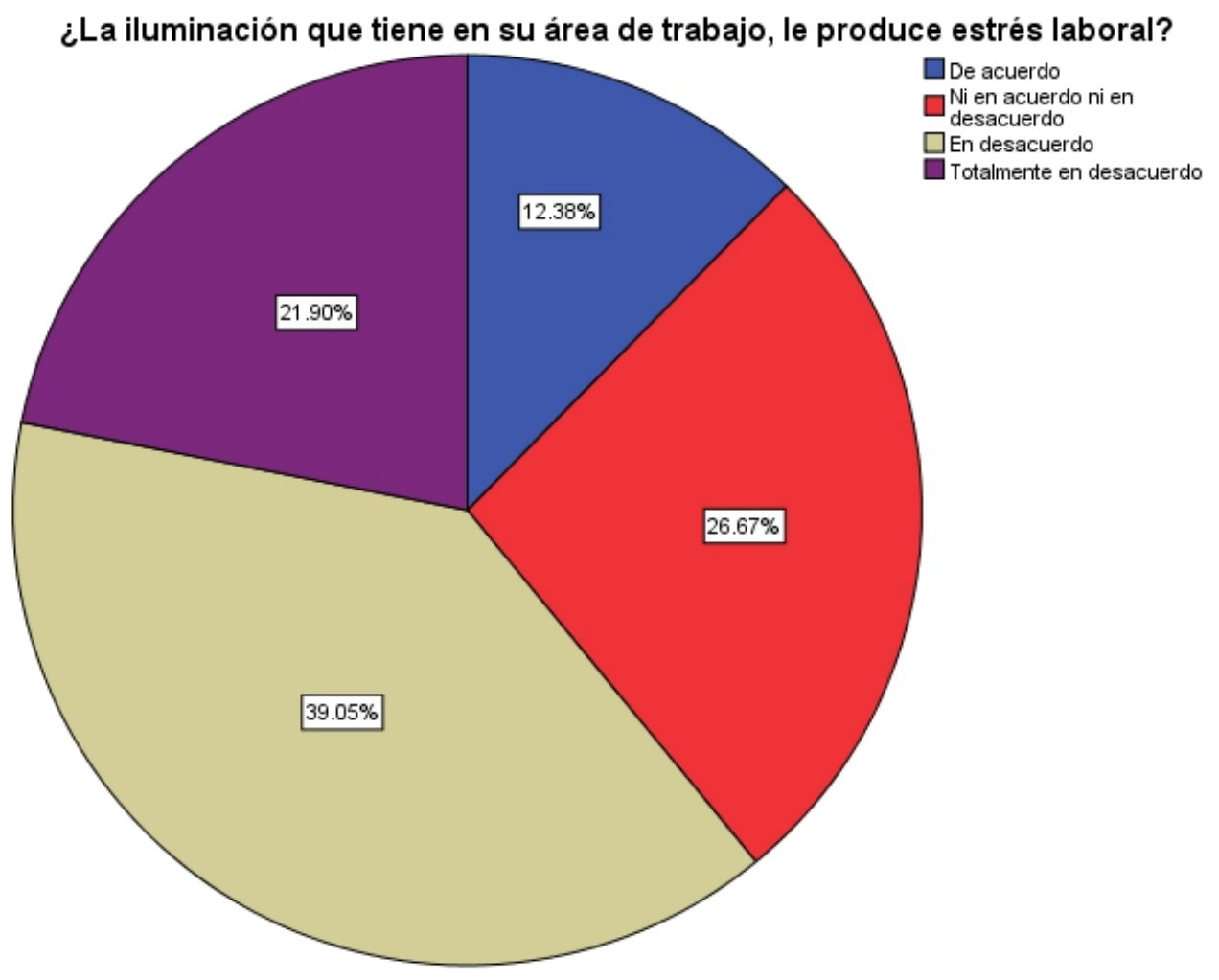

El 12.38\% del personal, está de acuerdo en que la iluminación que tiene en su área de trabajo, le produce estrés laboral, el 26.67\% respondió que ni de acuerdo ni en desacuerdo, es decir no saben sí o no, la iluminación que tiene en su área de trabajo, le produce estrés laboral. 39.05\% del personal está en desacuerdo que la iluminación que tiene en su área de trabajo, le produzca estrés laboral, y el $21.90 \%$ está totalmente en desacuerdo que la iluminación que tiene en su área de trabajo, le produzca estrés laboral. 


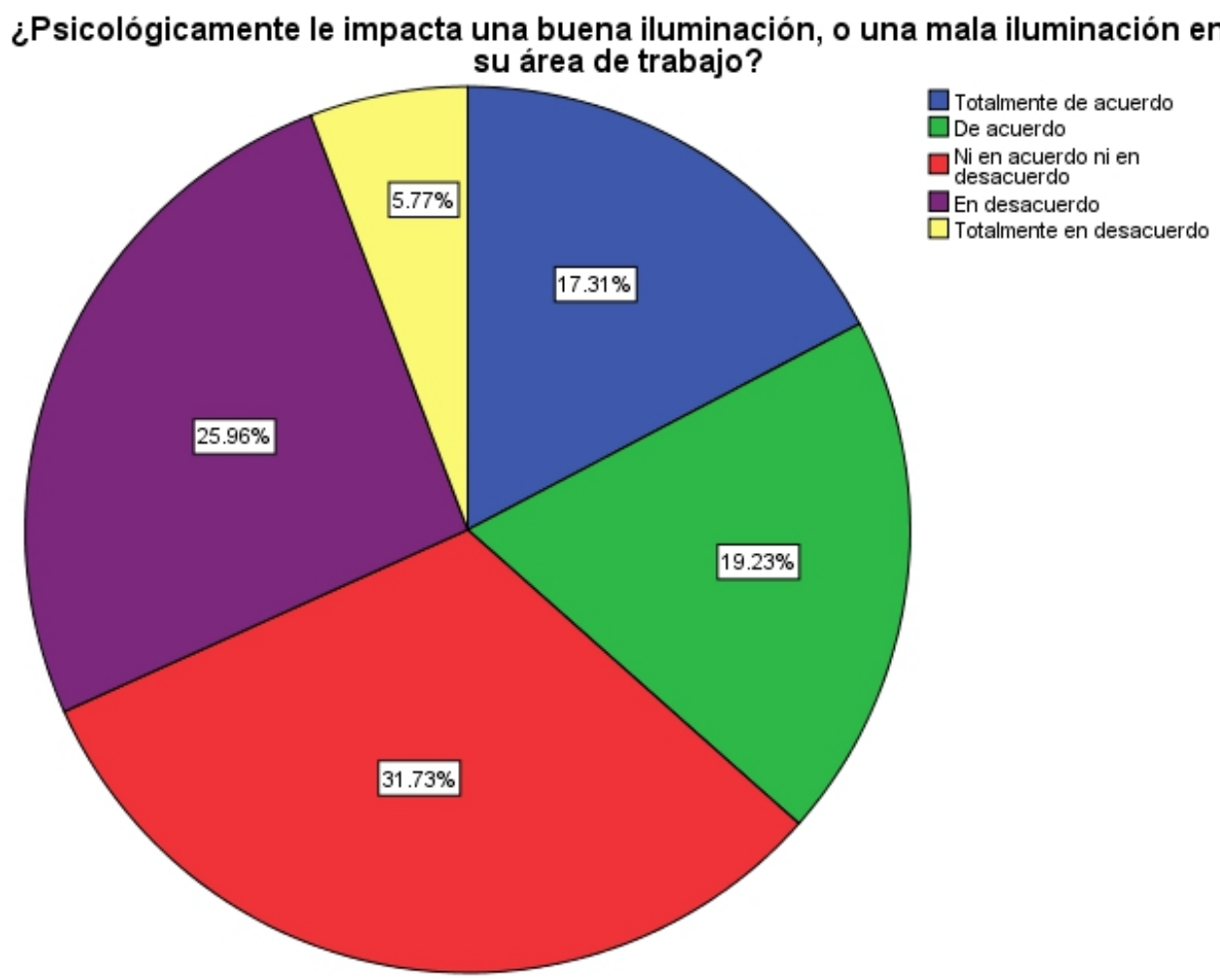

El $17.31 \%$ está totalmente de acuerdo en que psicológicamente le impacta una buena o mala iluminación en su área de trabajo, el $19.23 \%$ comenta estar de acuerdo que psicológicamente le impacta una buena iluminación, o una mala iluminación, en su área de trabajo, y el 31.73\% respondió que ni de acuerdo ni en desacuerdo, es decir no sabe sí, o no, psicológicamente le impacta una buena iluminación, o una mala iluminación en su área de trabajo, y el $25.96 \%$ del personal está en desacuerdo que, psicológicamente le impacte una buena o mala iluminación en su área de trabajo, y finalmente el $5.77 \%$ está totalmente en desacuerdo, que psicológicamente le impacte una buena o mala iluminación en su área de trabajo. 


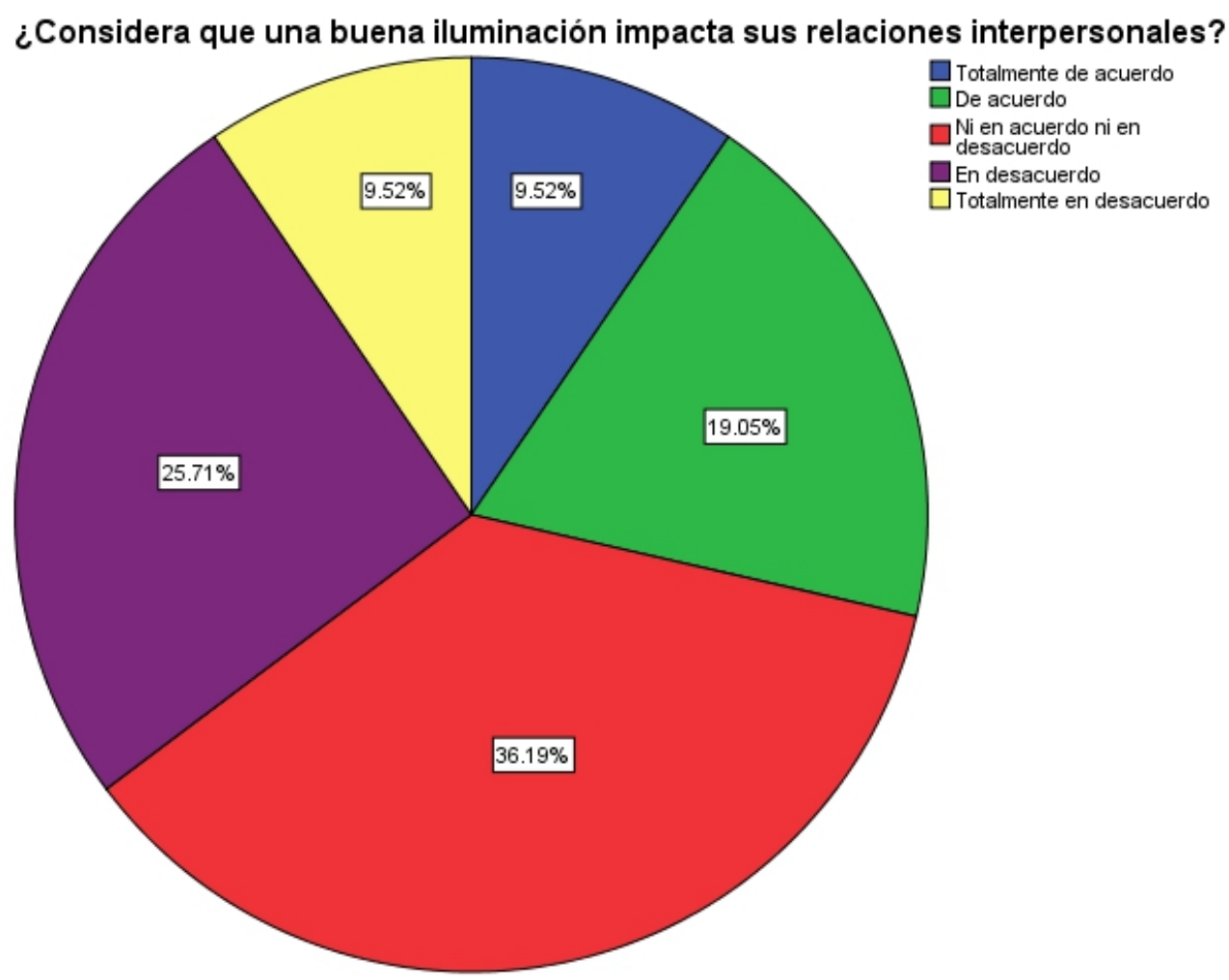

El 9.52\% contestó que está totalmente de acuerdo que una buena iluminación impacta sus relaciones interpersonales, el 19.05\% está de acuerdo que una buena iluminación impacta sus relaciones interpersonales, el 36.19\% contestó que, ni en acuerdo ni en desacuerdo, es decir no saben sí, o no, una buena iluminación impacta sus relaciones interpersonales. E1 25.71\% está en desacuerdo de que una buena iluminación impacte en sus relaciones interpersonales, y el $9.52 \%$ está totalmente en desacuerdo que una buena iluminación impacte en sus relaciones interpersonales. 


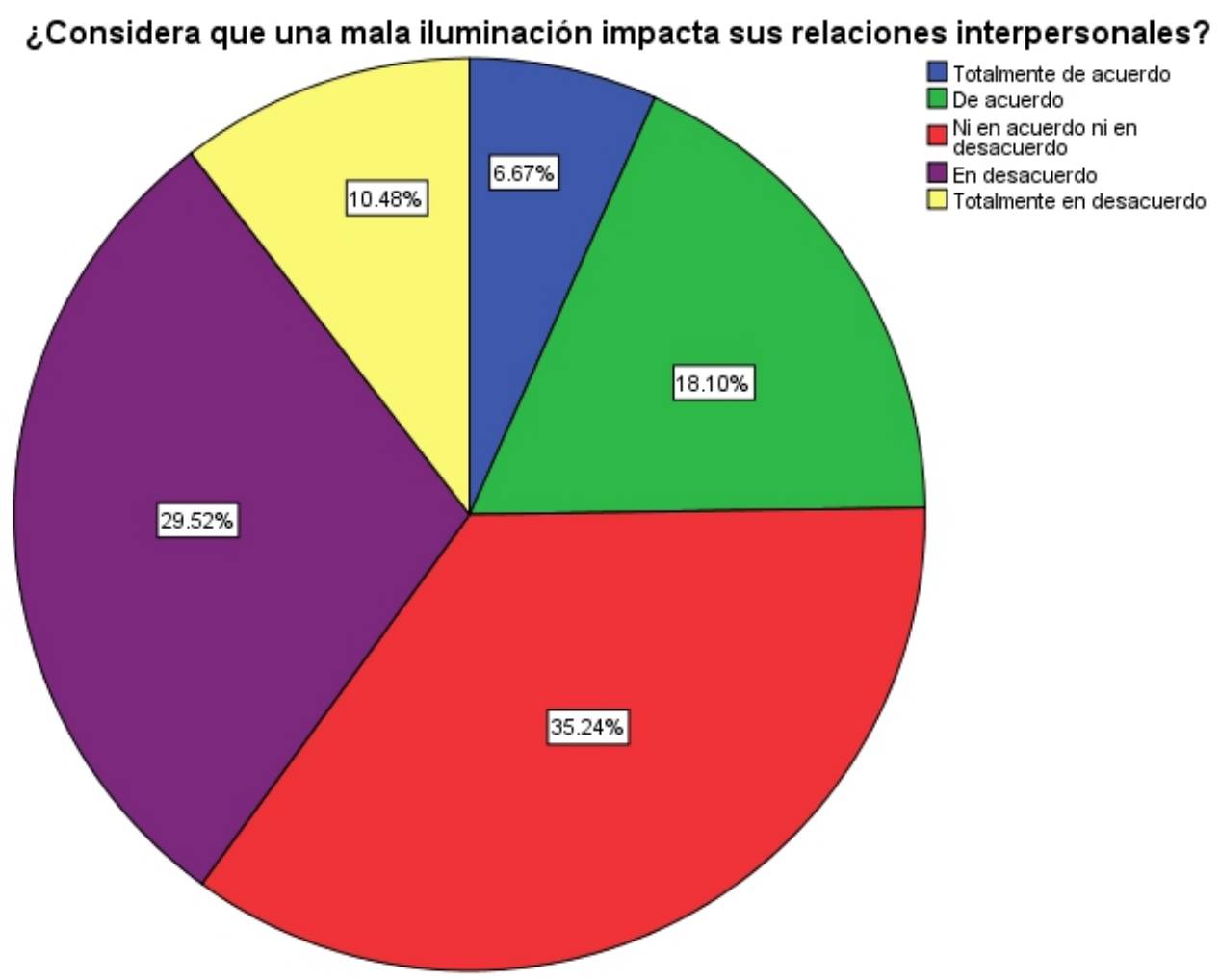

El $6.67 \%$ del personal de apoyo está totalmente de acuerdo en que considera que una mala iluminación impacta sus relaciones interpersonales, el $18.10 \%$ está de acuerdo en que una mala iluminación impacta sus relaciones interpersonales, el $35.24 \%$ opina estar ni de acuerdo ni en desacuerdo, es decir no saben si una mala iluminación impacta sus relaciones interpersonales. El $29.52 \%$ está en desacuerdo que una mala iluminación impacta sus relaciones interpersonales, y el $10.48 \%$ está en totalmente en desacuerdo que una mala iluminación impacta en sus relaciones interpersonales.

\section{Propuesta de mejora}

\section{Factor iluminación}

¿Considera que la iluminación que tiene en su área de trabajo impacta en su productividad laboral?

El $65.71 \%$ dice que si le afecta.

Estrategias de intervención:

a) Conocer los diversos espacios de trabajo, en los cuales, el personal de apoyo desempeña sus labores y que se ven afectado por la iluminación, para llevar a cabo mediciones, de los luxes de iluminación que se tienen y en caso de ser 
necesario, ajustarlo a la Norma Oficial Mexicana correspondiente

b) Conocer los diversos espacios de trabajo, en los cuales, el personal de apoyo desempeña sus labores y que se ven afectado por la iluminación, para llevar a cabo mediciones, de los luxes de iluminación que se tienen y en caso de ser necesario, ajustarlo a la Norma Oficial Mexicana correspondiente.

c) Definir las áreas que generan un mayor impacto resultante del $65.71 \%$ del personal de apoyo, que se ve afectado por la iluminación.

d) Revisar que las fuentes de iluminación no se encuentren bloqueadas y estén orientadas hacia el plano de trabajo.

1. ¿Le incomoda la iluminación en su lugar de trabajo?

El $42.86 \%$, si le incomoda

a) Identificar las características de las fuentes de iluminación que generan incomodidad al personal de apoyo.

2. ¿La iluminación que tiene en su área de trabajo, afecta su sistema visual?

El $25.71 \%$ no sabe si le afecta o no a su sistema visual la iluminación que tiene en su área de trabajo.

a) El desconocimiento sobre la afectación en el sistema visual debido a la iluminación puede ser mitigado mediante la generación de capacitaciones que concienticen al personal de la importancia de conocer cuando le afecta la iluminación a su sistema visual.

b) Concientización mediante folletos que expliquen de forma básica la importancia de una buena iluminación en el área de trabajo.

3. ¿La iluminación que tiene en su área de trabajo, ha afectado su sistema visual?

El 22.86\% contestó que no saben sí, la iluminación que tienen en su área de trabajo, ha afectado su sistema visual o no.

a) El desconocimiento sobre la afectación en el sistema visual debido a la iluminación puede ser mitigado mediante la generación de capacitaciones que concienticen al personal de la importancia de conocer cuando le afecta la iluminación a su sistema visual.

b) Concientización mediante folletos que expliquen de forma básica la importancia de una buena iluminación en el área de trabajo. 
c) Concientizar al personal de apoyo sobre realizarse exámenes de la vista al menos una vez al año.

4. ¿La iluminación que tiene en su área de trabajo, le produce estrés laboral?

El 26.67\% respondió que no saben sí la iluminación que tiene en su área de trabajo, le produce estrés laboral o no.

a) La fatiga visual desencadena en estrés laboral, por tanto será importante evitar trabajos prolongados en condiciones que afecten el sistema visual. Atendiendo a la estrategia anterior.

5. ¿Psicológicamente le impacta una buena iluminación, o una mala iluminación en su área de trabajo?

Al 36.54\% sí le impacta, mientras que al $31.73 \%$ no sabe si o no le impacta psicológicamente una buena o mala iluminación en su área de trabajo.

a) Identificar en grupos de trabajo (Máximo 20 personas), mediante la técnica lluvia de ideas, los aspectos psicológicos en los que afecta una buena o mala iluminación en el personal de apoyo.

b) Mediante los resultados de la estrategia anterior, generar informativos en donde se expliquen los aspectos psicológicos que se afectan con una buena o mala iluminación.

6. ¿Considera que una buena iluminación impacta sus relaciones interpersonales?

El 36.19\% no sabe si le impacta una buena o mala iluminación en sus relaciones interpersonales.

a) Identificar, de la estrategia anterior (causada por una buena o mala iluminación) si alguno de los aspectos psicológicos afecta en las relaciones interpersonales del personal de apoyo.

b) Dar a conocer los beneficios que otorga tener una buena iluminación en el área de trabajo tales como el confort, la seguridad, la salud del sistema visual y aspectos psicológicos positivos, que intervienen directamente en las relaciones interpersonales del personal de apoyo.

7. ¿Considera que una mala iluminación impacta en sus relaciones interpersonales?

El $35.24 \%$ no sabe si o no le afecta en sus relaciones interpersonales.

a) Identificar, de la estrategia anterior (causada por una buena o mala iluminación) si alguno de los aspectos psicológicos 
afecta en las relaciones interpersonales del personal de apoyo.

b) Dar a conocer los efectos negativos que otorga tener una buena iluminación en el área de trabajo tales como la incomodidad, la inseguridad, la afectación del sistema visual $\mathrm{y}$ aspectos psicológicos negativos, que intervienen directamente en las relaciones interpersonales del personal de apoyo.

\section{Conclusion}

Con el análisis de los datos, resultado de la aplicación del instrumento de recolección de información llegamos a las siguientes conclusiones:

La institución tiene un programa de examen de la vista para todos los trabajadores que necesitan revisión oftalmológica, pero se considera debe ser todo el personal, para evitar pérdida de visión prematura, debido a que no se tienen los niveles de iluminación adecuados en cada una de las áreas estudiadas. Decimos que todos deben hacer su examen de la vista ya que no todos acuden a realizarlo, algunos lo hacer por su propia cuenta. Y se considera el Instituto debe tener una base de datos de sus empleados por unidad académica de las condiciones visuales que reporta cada uno de acuerdo a su edad.

Debemos prestar puntual atención a los aspectos psicosociales debido a que los trabajadores reportan que sí les impactan los factores externos como internos y eso repercute en su productividad. Debido a ello se considera bastante delicado este punto para dar prontamente una alternativa de solución.

Se necesita llevar a cabo otra investigación, donde se pueda conocer, cuáles son los factores psicosociales que inciden en el buen desempeño y la productividad de los trabajadores de apoyo y asistencia a la educación, ya que nos podemos encontrar con el factor estrés, fatiga, presión laboral, acoso laboral, falta de apoyo por parte de los compañeros, depresión laboral, falta de apoyo del jefe inmediato, entre otros.

El estrés no siempre está provocado por factores psicosociales asociados al trabajo, si llegamos a tener problemas en casa, podríamos tener más dificultades a la hora de hacer frente al estrés laboral, ya que los problemas no desaparecen cuando vamos a trabajar. (Agencia europea para la Seguridad y salud en el trabajo, 2013). También cabe mencionar que los aspectos psicosociales y su relación con la salud laboral, no es nuevo aunque si la importancia y reconocimiento que ha adquirido en los últimos años (EUOSHA, 2002; Houdmont y Leka 2010; Naseall, Hellgren, Sverke, 2008). Como consecuencia de los importantes cambios en las organizaciones y de los procesos de globalización actual, la exposición a los riesgos psicosociales se ha hecho más frecuente e intensa, haciendo conveniente y necesario su 
identificación, evaluación y control con el fin de evitar riesgos asociados a la salud y la seguridad en el trabajo (EU-OSHA, 2007)

\section{References:}

1. Agencia Europea para la Seguridad en el trabajo (2007).

2. Acuerdo Marco Europeo sobre Violencia y acoso, publicado en el BOE de 14.1.2008.

3. Castelló, J. (2013). Resumen de una conferencia en la Cooperativa de Guissona. Instalaciones de iluminación en los criaderos de pollos. Selecciones avícolas Abril 2013. Recuperado http://seleccionesavicolas.com/avicultura/2013/04/instalaciones-deiluminacion-en-los-criaderos-de-pollos.

4. Darko, E., Heydarizadeh, P., Schoefs, B., \& Sabzalian, M. (2014). Photosynthesis under artificial light: the shift in primary and secondary metabolism. Phil. Trans. R. Soc. B 2014 369, 20130243, published 3 March 2014.

5. EU-OSHAS (2002). La EU-OSHA es la Agencia de información de la Unión Europea para la seguridad y la salud en el trabajo. Nuestro trabajo contribuye al Marco estratégico de la Comisión Europea en materia de salud y seguridad en el trabajo 2014-2020. https://osha.europa.eu/es/about-eu-osha

6. Harvey, H. \& Sloan, G. (2016). The science behind codes and standards for safe pedestrian walkways: Lighting and visual cues. Aplied Egonomics 52 (2016). Pp. 112-119.

7. Nakagawara, V.B., Montgomery, R.W., \& Wood, K.J. (2007). Aircraft accidents and incidents associated with visual effects from bright light exposures during lowlight flight operations. Optometry 78, Pp. 415420.

8. Obregón, S. (2016). Fundamentos de Ergonomía. México D.F. Editorial Patria. Pp. 109-134.

9. Ramos, A. (2007). "Estudio de factores de riesgo ergonómico que afectan el desempeño laboral de usuarios de equipo de cómputo en una institución educativa". Tesis de maestría para la obtención del grado de maestro en ciencias con especialidad en salud ocupacional, seguridad e higiene. ENMyH - IPN, México D.F. Pp. 55.

10. Secretaría del Trabajo y Previsión Social (2008). Condiciones de iluminación en los centros de trabajo. NOM-025-STPS-2008, Condiciones de iluminación en los centros de trabajo. 